\title{
Sistem Informasi Kehadiran Dosen dan Mahasiswa Menggunakan Sidik Jari pada Program Studi Informatika Universitas Tanjungpura
}

\author{
Agus Prasetyo Raharjo ${ }^{\# 1}$, Dr.Arif Bijaksana Putra Negara, S.T.,M,T.², Novi Safriadi, S.T., M.T.*3 \\ "Program Studi Informatika Universitas Tanjungpura \\ Jl. Prof. Dr. H. Hadari Nawawi, Pontianak 78124 \\ ${ }^{1}$ agusprasetyoraharjo@gmail.com \\ ${ }^{2}$ arifbpneinformatika. untan.ac.id \\ ${ }^{3}$ Safriadieinformatics.untan.ac.id
}

\begin{abstract}
Abstrak-Sistem informasi dalam pelaksanaan proses pembelajaran yang baik akan tercapai apabila didukung dengan kehadiran yang dapat dimonitoring dan dapat diolah secara otomatis. Proses presensi yang sudah ada di Program studi informatika Universitas Tanjungpura belum dapat dimonitoring atau masih secara manual khususnya seperti presensi mahasiswa. Presensi dalam proses perkuliahan dapat didukung dengan menggunakan alat presensi kehadiran berupa fingerprint scanner agar proses presensi dapat diolah secara otomatis. Fingerprint Scanner adalah perangkat otentikasi yang menggunakan identitas biometric dari penggunanya. Alat yang digunakan dapat dihubungkan dengan antar muka website terhadap data yang telah disimpan dari fingerprint scanner. Dokumen pada website disebut dengan web page dan link dalam website memungkinkan pengguna bisa berpindah dari satu page ke page lain (hyper text) dan terkoneksi dalam satu jaringan. Website yang digunakan untuk menampilkan informasi kehadiran mahasiswa dan dosen terhadap jadwal matakuliah. Penelitian ini Menghasilkan sistem informasi yang dapat membantu program studi dalam pelaksanaan monitoring perkuliahan serta membantu dosen dalam mengevaluasi kehadiran mahasiswa. Penelitian ini menggunakan tiga pengujian yaitu black box, kuisoner validitas dan kuisoner reabilitas. Pengujian kuisoner bertujuan untuk mengetahui tingkat keberhasilan dari sistem yang dibuat. Pengujian validitas kuesioner pada penelitian ini menggunakan koefisien korelasi Pearson. Pertanyaan dinyatakan valid jika nilai korelasi Pearson lebih besar dari nilai rtabel, dan jika sebaliknya maka pertanyaan dinyatakan tidak valid. Pengujian reliabilitas kuesioner ini menggunakan metode Cronbach's Alpha untuk mengukur kestabilan dan konsistensi responden dalam menjawab pertanyaan. Berdasarkan hasil pengujian disimpulkan bahwa pengujian yang dilakukan aplikasi dapat dimonitring dengan baik dan pengujian kusioner dinilai positif dan berhasil.

Kata Kunci- Sistem informasi, Proses presensi, Fingerprint scanner, Website, Pengujian Kuisoner.
\end{abstract}

\section{PENDAHULUAN}

Sistem Informasi dalam pelaksanaan proses pembelajaran yang baik akan tercapai apabila didukung dengan kehadiran yang dapat dimonitoring dan dapat diolah secara otomatis. Proses monitoring presensi dalam pelaksanaan perkuliahan mempunyai peranan penting dalam memandu mahasiswa maupun dosen agar pelaksanaan perkuliahan tersebut berjalan dengan baik. Oleh karena itu, Mahasiswa maupun Dosen harus mengisi data presensi masing-masing agar proses pembelajaran dapat berlangsung.Proses presensi yang sudah ada di Program studi informatika Universitas Tanjungpura belum dapat dimonitoring atau masih secara manual khususnya seperti presensi mahasiswa. Presensi yang dilakukan saat ini ditandai dengan paraf menggunakan bolpoin oleh mahasiswa yang menyatakan kehadirannya selain itu dapat dimanipulasi oleh mahasiswa yang tidak hadir dengan cara memalsukan parafnya dan Presensi yang dilakukan oleh dosen sudah ada tetapi pengambilan data belum secara otomatis. Presensi dalam proses perkuliahan yang ada saat ini dapat didukung dengan menggunakan alat presensi kehadiran berupa fingerprint scanner agar proses presensi dapat diolah secara otomatis

Fingerprint Scanner adalah perangkat otentikasi yang menggunakan identitas biometric dari penggunanya. Sesuai dengan namanya, fingerprint scanner juga disebut sebagai alat khusus untuk mendeteksi sidik jari penggunanya. Fingerprint scanner mulai banyak digunakan secara terintegrasi dengan notebook dan beberapa perangkat pendukung lainnya. Fingerprint Scanner berperan penting dalam memudahkan pengolahan data presensi. Alat yang digunakan dapat dihubungkan dengan antar muka website terhadap data yang telah disimpan dari fingerprint scanner. 
Website merupakan fasilitas internet yang menghubungkan dokumen dalam lingkup lokal maupun jarak jauh. Dokumen pada website disebut dengan web page dan link dalam website memungkinkan pengguna bisa berpindah dari satu page ke page lain ( hyper text) dan terkoneksi dalam satu jaringan. Website yang digunakan untuk menampilkan informasi kehadiran mahasiswa dan dosen terhadap jadwal matakuliah.

Berdasarkan permasalahan yang ditemukan, seperti presensi kehadiran mahasiswa data dosen belum dapat dimonitoring dan masih secara manual, maka penelitian ini mengembangkan aplikasi berbasis web yang dapat memonitoring dan mengolah data presensi dalam proses perkuliahan.

\section{II.TINJAUAN PUSTAKA}

\section{A. Pengertian Monitoring}

Monitoring adalah penilaian yang skematis dan terus menerus terhadap kemajuan suatu pekerjaan. Sedangkan Menurut WHO Monitoring adalah suatu proses pengumpulan dan menganalisis informasi dari penerapan suatu program termasuk mengecek secara reguler untuk melihat apakah kegiatan (program) itu berjalan sesuai rencana sehingga masalah yang dilihat (ditemui) dapat diatasi. [1].

\section{B. Entity Relationship Diagram (ERD)}

ERD merupakan suatu model untuk menjelaskan hubungan antar data dalam basis data berdasarkan objek-objek dasar data yang mempunyai hubungan antar relasi. ERD memodelkan struktur data dan hubungan antar data, untuk menggambarkannya digunakan notasi dan simbol. [4].

\section{Flowchart (Diagram Alir)}

Sistem flowchart merupakan bagan yang menunjukan arus pekerjaan secara keseluruhan dari sistem. Bagan ini menjelaskan urutan-urutan dari prosedurprosedur yang ada didalam system. [4].

\section{Sublime}

Sublime merupakan aplikasi editor untuk kode dan teks yang dapat berjalan diberbagai platform operating system dengan menggunakan teknologi Phyton API. 2.12. Sublime Text mendukung berbagai bahasa pemrograman dan mampu menyajikan fitur syntax highlight hampir di semua bahasa pemrogramman yang didukung ataupun dikembangkan oleh komunitas seperti; C, C++, C\#, CSS, D, Dylan, Erlang, HTML, Groovy, Haskell, Java, JavaScript, LaTeX, Lisp, Lua, Markdown, MATLAB, OCaml, Perl, PHP, Python, R, Ruby, SQL, TCL, Textile and XML. Biasanya bagi bahasa pemrograman yang didukung ataupun belum terdukung secara default dapat lebih dimaksimalkan atau didukung dengan menggunakan add-ons yang bisa didownload sesuai kebutuhan user.

\section{E. Хатрp}

Merupakan paket server web PHP dan database MySQL yang paling popular dikalangan pengembang web dengan menggunakan PHP dan MySQL sebagai databasenya. [2].

\section{F. PHP}

Hypertext Preprocessor adalah bahasa skrip yang dapat ditanamkan atau disisipkan ke dalam HTML. PHP banyak dipakai untuk memprogram situs web dinamis. PHP dapat digunakan untuk membangun sebuah CMS. [2].

\section{G.MYSQL}

MySQL adalah salah satu jenis database server yang sangat terkenal dan banyak digunakan untuk membangun aplikasi yang menggunakan database sebagai sumber dan pengolahan datanya" [2]. MySQL adalah salah satu jenis server yang ada diantara banyak server database [5].

\section{METOLOGI PENELITIAN}

\section{A. Data Penelitian}

Data penelitian berupa data kehadiran Mahasiswa dalam proses pelaksanaan perkuliahan yang dilaksanakan di Gedung Informatika UNTAN, baik berupa data Dosen beserta sidik jari, Mahasiswa beserta sidik jari, jadwal perkuliahan, daftar kehadiran dosen, dan daftar kehadiran mahasiswa.

\section{B. Perangkat Penelitian}

Perangkat penelitian yang digunakan dalam penelitian ini terdiri dari perangkat keras dan perangkat lunak. Adapun perangkat yang digunakan diantaranya, yaitu perangkat keras Laptop Asus A455L dengan spesifikasi Posesor Intel Core i34030U , 1,90 GHz, Ram 6072MB, VGA NVIDIA GEFORCE 820M, HDD 500GB dan Fingerspot Tipe Revo D-152NB. Perangkat lunak yang digunakan dalam penelitian ini adalah, Sistem Operasi Windows 7 Ultimate 64 Bit,Sublime text,Xampp, Corel Draw 7, Microsoft Office Visio 2010, dan KitaServer V.1.0.1.1.

\section{C.Metodologi Penelitian}

Adapun langkah-langkah pada metode penelitian diberikan Gambar 1. Diagram Alir Penelitian.

Metode penelitian diawali dengan analisa kebutuhan, kebutuhan sistem, desain sistem, implementasi sistem, pengujian sistem, analisa hasil pengujian, dan penarikan kesimpulan. 


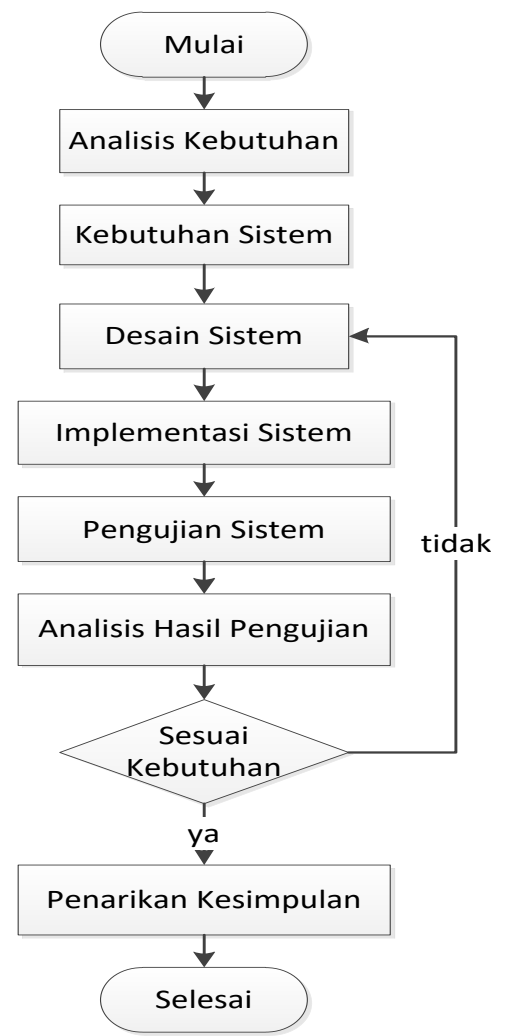

Gambar 1. Diagram Alir Penelitian

D.Arsitektur Sistem

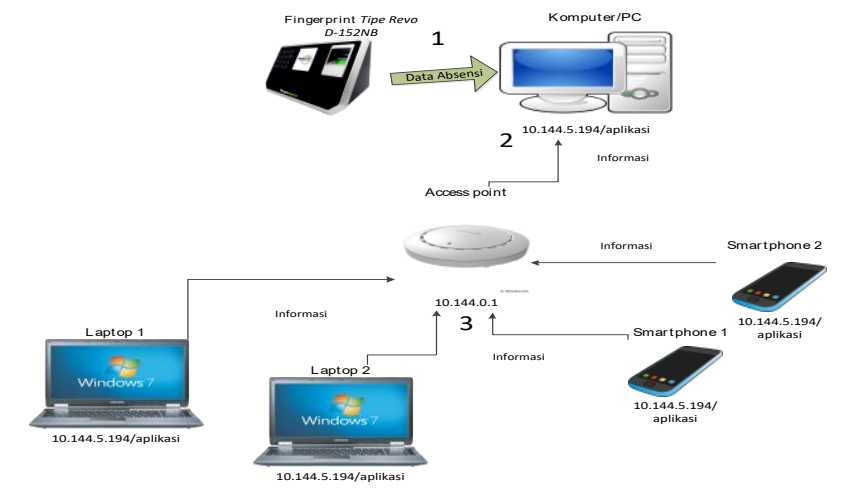

Gambar 2. Rancangan Arsitektur Sistem

Skenario inti/ringkas dari proses sistem informasi yang diusulkan adalah sebagai berikut :

- Komputer/PC menerima data dari Alat Finferprint Scanner Tipe Revo D-152NB.

- Komputer/PC sebagai server Local dan dihubungkan kedalam 1 jaringan dengan IP static 192.168.1.28 agar IP tersebut menuju ke server local.

- Perangkat lainnya dapat mengakses ke server local dengan alamat 192.168.1.28/presensi .

\section{E. Diagram Alir Sistem}

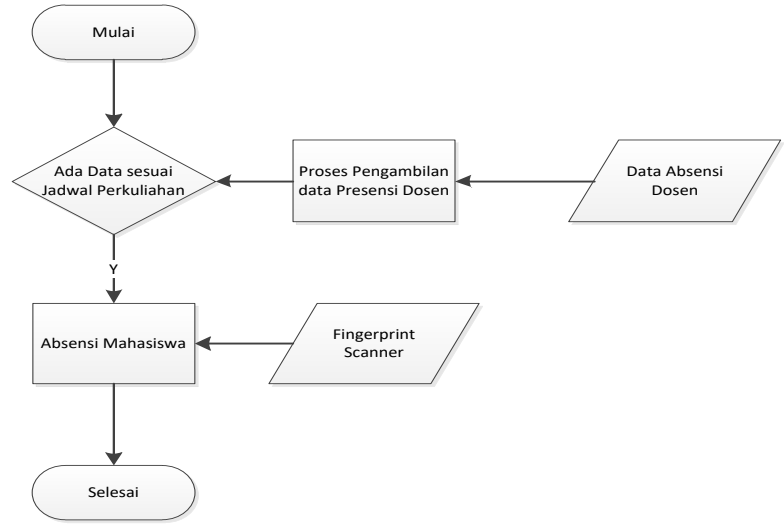

Gambar 3. Diagram Alir sistem presensi kehadiran

\section{F. Perancangan Antarmuka}

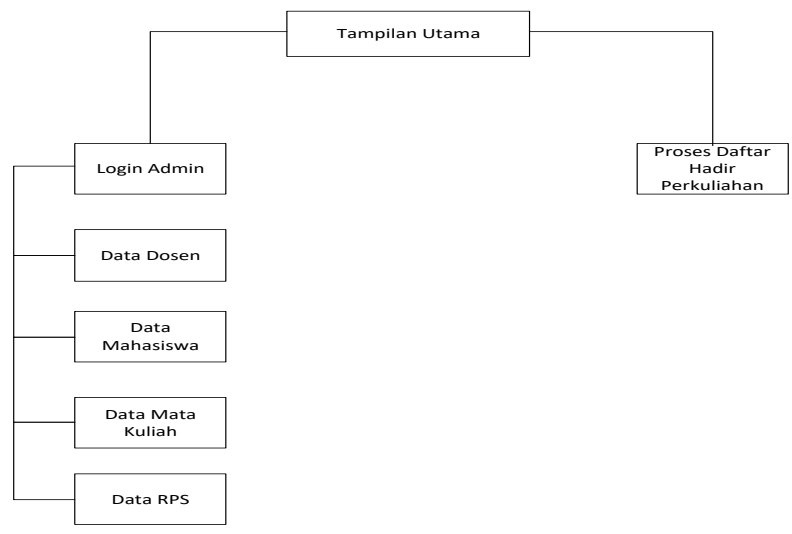

Gambar 4. Rancangan Antarmuka

\section{G.Perancangan Basis data}

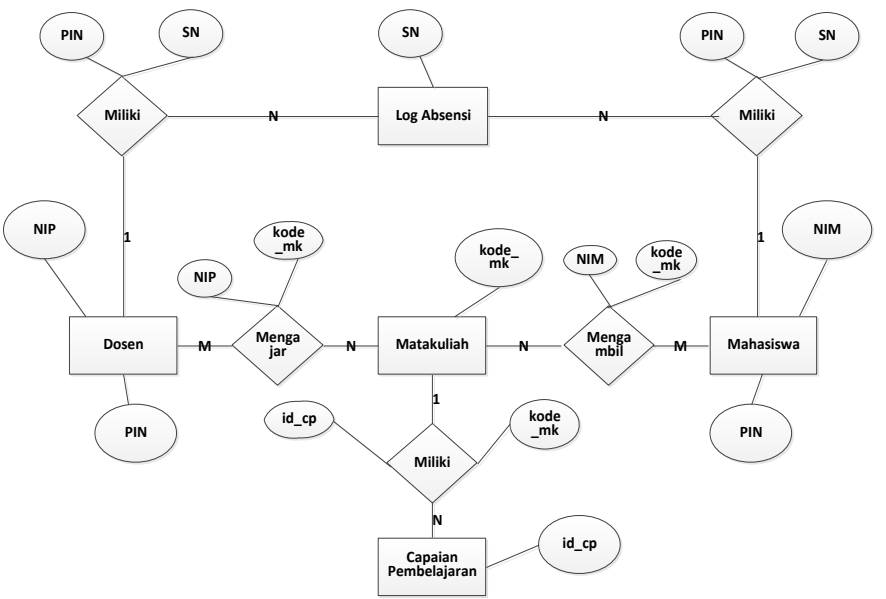

Gambar 5. Entity Relationship Diagram 


\section{H.Pengujian Sistem}

- Pengujian Black box

Tabel 1. Perancangan Hasil Pengujian

\begin{tabular}{|c|c|c|c|c|}
\hline Input & \multicolumn{2}{|c|}{ Contoh Data } & $\begin{array}{c}\text { Hasil } \\
\text { Eksekusi }\end{array}$ & Keterangan \\
\hline \multirow{3}{*}{$\begin{array}{l}\text { Data } \\
\text { kosong }\end{array}$} & Username & Kosong & & \\
\hline & Password & Kosong & & \\
\hline & Status & Salah & & \\
\hline \multirow{3}{*}{$\begin{array}{c}\text { Data } \\
\text { Salah } \\
\text { Satu } \\
\text { Kosong }\end{array}$} & Username & Kosong & & \\
\hline & Password & Ada & & \\
\hline & Status & Salah & & \\
\hline \multirow{3}{*}{$\begin{array}{l}\text { Data } \\
\text { Salah }\end{array}$} & Username & Ada & & \\
\hline & Password & Ada & & \\
\hline & Status & Salah & & \\
\hline \multirow{3}{*}{$\begin{array}{c}\text { Data } \\
\text { Benar } \\
\text { dan } \\
\text { Lengkap }\end{array}$} & Username & Ada & & \\
\hline & Password & Ada & & \\
\hline & Status & Benar & & \\
\hline
\end{tabular}

- Pengujian Kuisoner

Tabel 2. Perancangan Hasil kuisoner

\begin{tabular}{|c|c|c|c|c|c|c|}
\hline \multirow{2}{*}{ Responden } & \multicolumn{5}{|c|}{ Total } \\
\cline { 2 - 7 } & 1 & 2 & 3 & 4 & 5 & \\
\hline 1 & & & & & & \\
\hline$\cdots$ & & & & & & \\
\hline 10 & & & & & & \\
\hline
\end{tabular}

\section{HASIL DAN ANALISIS}

Pada Bab ini akan dilakukan implementasi dan hasil pengujian terhadap aplikasi. Tahapan ini dilakukan setelah perancangan sistem selesai dan selanjutnya akan diimplementasikan kemudian dilakukan pengujian terhadap aplikasi. Implementasi dan hasil pengujian yang dilakukan untuk mengetahui aplikasi tersebut dapat berjalan sesuai dengan tujuannya atau tidak.

\section{A. Implementasi}

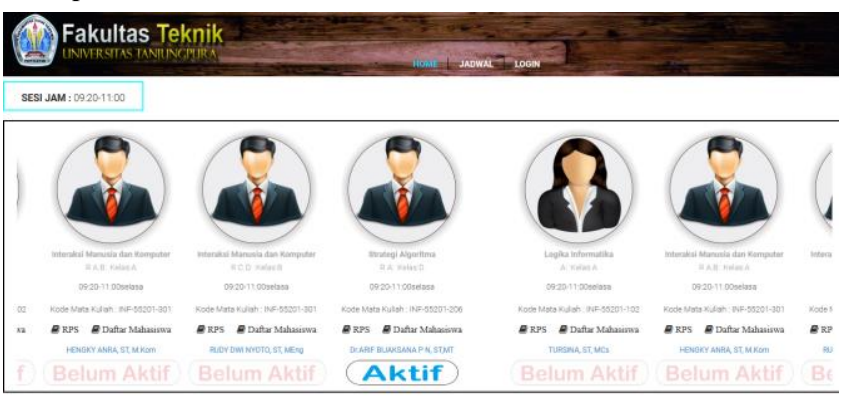

Gambar 6. Antarmuka Halaman Utama
Aplikasi Monitoring Dosen dan Mahasiswa prodi informatika universitas tanjungpura dapat dilihat pada gambar berikut :

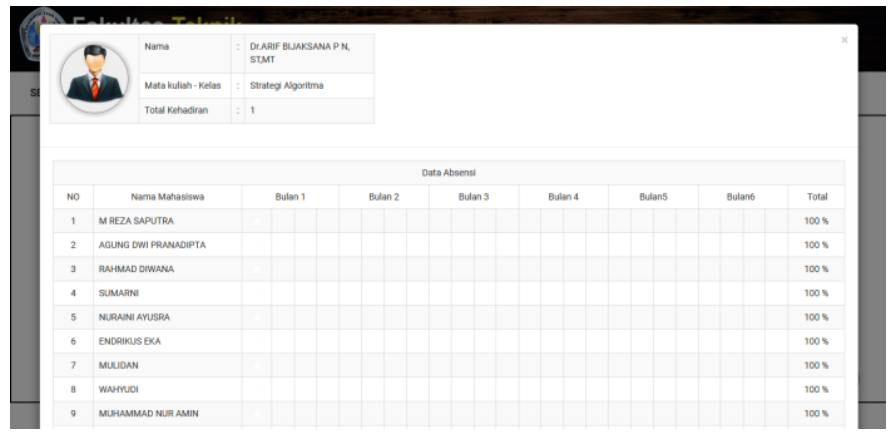

Gambar 7. Antarmuka Kehadiran Mahasiswa

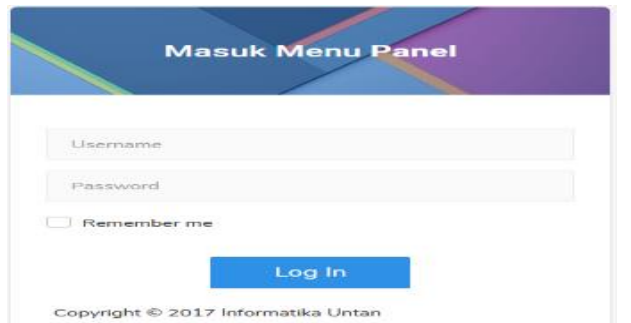

Gambar 8. Antarmuka Login

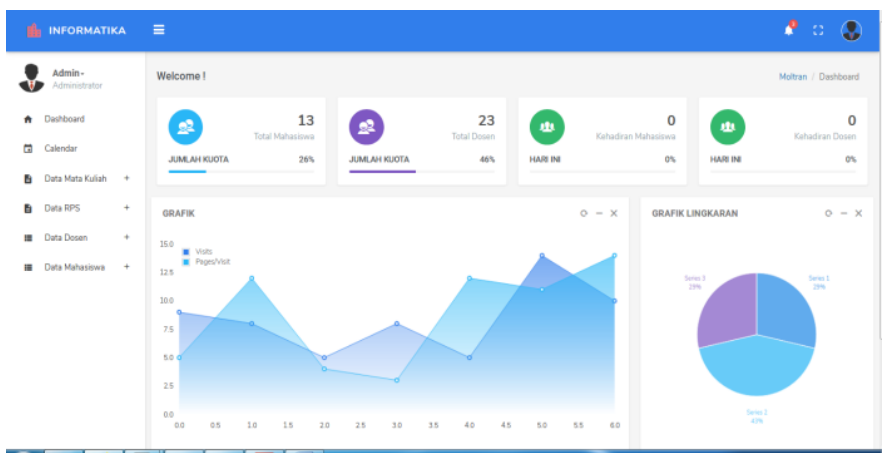

Gambar 8. Antarmuka Halaman Utama Login

\section{B. Pengujian Black box}

Pengujian black box pada penelitian ini terdiri pengujian login, pengambilan data mesin fingerprint, pengujian isi data absen, import data, dan pengujian tambah data.

Tabel 3. Hasil Pengujian Login

\begin{tabular}{|c|c|c|c|c|}
\hline \multirow{2}{*}{ Input } & \multicolumn{2}{|c|}{ Contoh Data } & $\begin{array}{c}\text { Hasil } \\
\text { Eksekusi }\end{array}$ & Keterangan \\
\hline \multirow{2}{*}{$\begin{array}{c}\text { Data } \\
\text { kosong }\end{array}$} & Username & Kosong & \multirow{2}{*}{$\begin{array}{c}\text { Tidak } \\
\text { Berhasil }\end{array}$} & $\begin{array}{c}\text { Pesan Kesalahan: } \\
\text { "Please fill out } \\
\text { this fileld" }\end{array}$ \\
\cline { 2 - 3 } & Ptatus & Admin & Kosong & Pesan Kesalahan: \\
\hline Data & Username & Admin & Tidak & Pesan \\
\hline
\end{tabular}


JUSTIN (Jurnal Sistem dan Teknologi Informasi) Vol. 6 , No. 2 , April 2018

\begin{tabular}{|c|c|c|c|c|}
\hline $\begin{array}{c}\text { Salah } \\
\text { Satu } \\
\text { Kosong }\end{array}$ & Password & Kosong & Berhasil & "Please fill out \\
\cline { 2 - 3 } this fileld"
\end{tabular}

Tabel 4. Hasil Pengujian Pengambilan data Fingerprint

\begin{tabular}{|c|c|c|c|}
\hline Input & Contoh Data & Hasil Eksekusi & Keterangan \\
\hline \multirow{2}{*}{ Data Kosong } & Kosong & Tidak Berhasil & $\begin{array}{c}\text { "Data Absen } \\
\text { Tidak Tertampil" } \\
\text { Gambar 4.10 }\end{array}$ \\
\hline Data Berhasil & \multirow{2}{*}{ Data ada } & Berhasil & "Data Absen \\
diambil & & & Tertampil" \\
& & & Gambar 4.11 \\
\hline
\end{tabular}

Tabel 4. Hasil Pengujian Isi Data Absen

\begin{tabular}{|c|c|c|c|c|}
\hline Input & \multicolumn{2}{|c|}{ Contoh Data } & $\begin{array}{c}\text { Hasil } \\
\text { Eksekusi }\end{array}$ & Keterangan \\
\hline $\begin{array}{c}\text { Input Data } \\
\text { Absen sidik jari } \\
\text { tidak sesuai } \\
\text { jadwal } \\
\text { perkuliahan }\end{array}$ & $\begin{array}{c}\text { Data } \\
\text { Nomor }\end{array}$ & 123 & $\begin{array}{c}\text { Tidak } \\
\text { berhasil }\end{array}$ & $\begin{array}{c}\text { Pesan Kesalahan } \\
\text { "Data Absen tidak } \\
\text { tampil" }\end{array}$ \\
\hline $\begin{array}{c}\text { Input Data } \\
\text { Absen sidik jari } \\
\text { sesuai jadwal } \\
\text { perkuliahan }\end{array}$ & $\begin{array}{c}\text { Domor } \\
\text { Pin }\end{array}$ & 123 & Berhasil & $\begin{array}{c}\text { "Data Absen akan } \\
\text { tampil sesuai jadwal } \\
\text { perkuliahan }\end{array}$ \\
\hline
\end{tabular}

\section{C.Pengujian Kuisoner}

Pengujian kuisioner pada penelitian ini terdiri dari pengujian validitas kuisioner, reabilitas kuisioner, dan User Acceptance Test yang diukur dengan Likert's Summated Rating (LSR). Pengujian ini dilakukan terhadap dosen Program Studi Teknik Informatika Universitas Tanjungpura, total populasi dosen berjumlah 10 orang, kuisioner disebarkan ke 10 orang responden, kuisioner pengujian aplikasi dilampirkan pada Lampiran $\mathrm{F}$, hasil dari kuisioner tersebut dapat dilihat pada Tabel berikat :

Tabel 4. Total Skor Responden

\begin{tabular}{|l|l|c|c|c|c|c|c|}
\hline \multirow{2}{*}{ No } & Responden & \multicolumn{5}{|c|}{ Item } & \multirow{2}{*}{ Total } \\
\cline { 3 - 7 } & & 1 & 2 & 3 & 4 & 5 & \\
\hline 1 & Tri Herianto/ D1041151057 & 4 & 4 & 4 & 4 & 4 & 20 \\
\hline 2 & Weike Alen Phinjaya / D1041151047 & 3 & 3 & 3 & 4 & 4 & 17 \\
\hline
\end{tabular}

Korespondensi : Agus Prasetyo Raharjo

\begin{tabular}{|c|c|c|c|c|c|c|c|}
\hline 3 & Kwartarini / D1041151075 & 5 & 5 & 4 & 5 & 5 & 24 \\
\hline 4 & Welly / D1041151013 & 4 & 4 & 4 & 5 & 5 & 22 \\
\hline 5 & Sigit Heru Prakoso/ D1041151035 & 4 & 4 & 5 & 5 & 4 & 22 \\
\hline 6 & Coenelius Venti/ D1041151019 & 3 & 4 & 3 & 4 & 5 & 19 \\
\hline 7 & Anyap Lius / D1041151049 & 4 & 4 & 4 & 4 & 4 & 20 \\
\hline 8 & Agung Dwi Pranadipta/ D1041151063 & 4 & 5 & 4 & 5 & 4 & 22 \\
\hline 9 & Egon Suparius Ipo/ D1041151051 & 4 & 4 & 4 & 5 & 4 & 21 \\
\hline 10 & $\begin{array}{l}\text { Dr.ARIF BIJAKSANA P N, ST,MT / } \\
197208081998021002\end{array}$ & 4 & 4 & 4 & 4 & 4 & 20 \\
\hline \multicolumn{7}{|c|}{ TOTAL } & 207 \\
\hline
\end{tabular}

Tabel 5. Hasil Pengujian Validitas kuisoner

\begin{tabular}{|c|c|c|c|}
\hline $\begin{array}{c}\text { Korelasi } \\
\text { antara }\end{array}$ & $\begin{array}{c}\text { Nilai Korelasi } \\
\text { (Pearson } \\
\text { Corellation) }\end{array}$ & $\begin{array}{c}\text { Hubungan } \\
\text { rtable }= \\
\mathbf{0 , 5 4 9 3 5 7}\end{array}$ & Kesimpulan \\
\hline $\begin{array}{c}\text { Variabel No. } 1 \\
\text { dengan Total }\end{array}$ & 0,609 & Lebih dari & Valid \\
\hline $\begin{array}{c}\text { Variabel No.2 } \\
\text { dengan Total }\end{array}$ & 0,611 & Lebih dari & Valid \\
\hline $\begin{array}{c}\text { Variabel No. } 3 \\
\text { dengan Total }\end{array}$ & 0,607 & Lebih dari & Valid \\
\hline $\begin{array}{c}\text { Variabel No. } 4 \\
\text { dengan Total }\end{array}$ & 0,608 & Lebih dari & Valid \\
\hline $\begin{array}{c}\text { Variabel No. 5 } \\
\text { dengan Total }\end{array}$ & 0,608 & Lebih dari & Valid \\
\hline $\begin{array}{c}\text { Variabel No. } 6 \\
\text { dengan Total }\end{array}$ & 0,610 & Lebih dari & Valid \\
\hline $\begin{array}{c}\text { Variabel No. } 7 \\
\text { dengan Total }\end{array}$ & 0,609 & Lebih dari & Valid \\
\hline $\begin{array}{c}\text { Variabel No. } 8 \\
\text { dengan Total }\end{array}$ & 0,608 & Lebih dari & Valid \\
\hline $\begin{array}{c}\text { Variabel No. } 9 \\
\text { dengan Total }\end{array}$ & 0,609 & Lebih dari & Valid \\
\hline $\begin{array}{c}\text { Variabel No. } \\
\text { 10 dengan } \\
\text { Total }\end{array}$ & 0,609 & Lebih dari & Valid \\
\hline
\end{tabular}

\section{D.User Acceptance Test (UAT)}

Pada tabel 4.6 ditunjukkan skor yang diperoleh pada pengujian UAT dosen dari 12 responden terhadap 5 item pertanyaan. Berikut perhitungan untuk mengukur UAT dosen terhadap aplikasi dengan menggunakan metode Likert's Summated Rating (LSR) pada pengujian dosen.

a. Jumlah skor untuk setiap responden:

- Skor maksimal $=5 \times 5$ item $=25$

- Skor minimal $=1 \times 5$ item $=5$

- Skor median $=3 \times 5$ item $=15$

- Skor kuartil $\mathrm{I}=2 \times 5$ item $=10$

- Skor kuartil III $=4$ x 5 item $=20$

b. Jumlah skor untuk seluruh responden:

- Maksimal $=25 \times 10$ responden $=250$

- Minimal $=5 \times 10$ responden $=50$ 
- Median $=17 \times 10$ responden $=170$

- Kuartil $\mathrm{I}=10 \times 10$ responden $=100$

- Kuartil III $=20 \times 10$ responden $=200$

c. Intepretasi jumlah skor tersebut adalah:

- $250<$ Skor $\leq 200$, artinya sangat positif (program dinilai berhasil)

- $200<$ Skor $\leq 170$, artinya positif (program dinilai cukup berhasil)

- $170<$ Skor $\leq 100$, artinya negatif (program dinilai kurang berhasil)

- $100 \leq$ Skor $\leq 50$, artinya sangat negatif (program dinilai tidak berhasil)

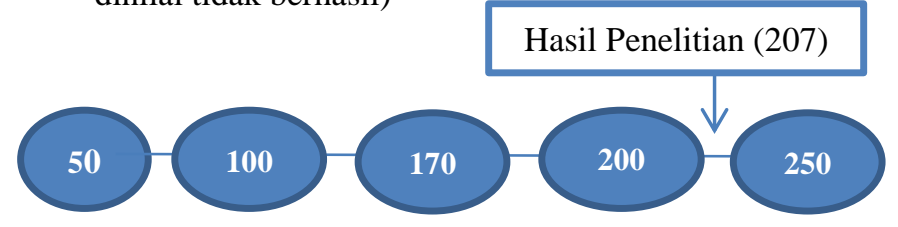

\section{V.KESIMPULAN/RINGKASAN}

Setelah dilakukan pengujian dan analisis terhadap Sistem Informasi Kehadiran Dosen dan Mahasiswa Pada Program Studi Teknik Informatika Universitas Tanjungpura, dapat disimpulkan sebagai berikut.

1. Sistem informasi ini dapat mendata absensi dan me monitoring kehadiran serta mengevaluasi kehadiran mahasiswa pada Program Studi Teknik Informatika Universitas Tanjungpura.

2. Hasil pengujian black box menunjukkan bahwa sistem dapat bekerja dengan baik dalam menangani suatu kemungkinan kesalahan input-an.

3. Berdasarkan hasil User Acceptace Test, sistem dinilai sangat positif dan berhasil.

Adapun beberapa hal yang menjadi saran dalam pengembangan sistem informasi yang baru dirancang ini agar menjadi lebih baik yaitu sebagai berikut :

1. Sistem informasi Kehadiran pada Program Studi Teknik informatika dapat dikembangkan dengan menghubungkan SIAKAD UNTAN terhadap Kehadiran .Mahasiswa dan Dosen.

2. Pengambilan data sidik jari mahasiswa dapat dilaksanakan langsung pada saat pendaftaran ulang mahasiswa.

\section{DAFTAR PUSTAKA}

[1] Kriyan Andika Jaya, "Aplikasi Monitoring dan Evaluasi Kinerja Aparatur di Kejaksaan Negeri Mempawah", JustIN Vol. 6, No. 1, (2018).

[2] M. Arief, Pemrograman Web Dinamis Menggunakan Php dan Mysql, Yogyakarta: ANDI, 2011.

[3] Muhammad Hari Mardiansyah "Rancang Bangun Aplikasi Pemantauan Kehadiran Dosen Dan Mahasiswa Pada Program Percepatan Angka Partisipasi Kasar (Apk) Berbasis Web” 2017.
[4] Munawar. 2005. Pemodelan Visual dengan UML. Penerbit GRAHA ILMU.

[5] R. Hidayat and R. Setiawan, "Perancangan Aplikasi Pemetaan Sarana Olahraga (PSO) Berbasis Website dan Selular Sebagai Informasi untuk Memetakan Sarana Olahraga," (JEPIN), Vol 3, No 1,p. 6, 2017. 